\title{
APLIKASI ANALISIS KORESPONDENSI UNTUK MELIHAT KARAKTERISTIK USAHA PARIWISATA DI PROVINSI BALI
}

\author{
Agust Wiras Ardi Kusuma $^{1 \S}$, I Gusti Ayu Made Srinadi ${ }^{2}$, Kartika Sari $^{3}$ \\ ${ }^{1}$ Jurusan Matematika, Fakultas MIPA - Universitas Udayana [Email: wirasardi@ gmail.com] \\ ${ }^{2}$ Jurusan Matematika, Fakultas MIPA - Universitas Udayana [Email: srinadi@ unud.ac.id] \\ ${ }^{3}$ Jurusan Matematika, Fakultas MIPA - Universitas Udayana [Email: sari_kaartika @ yahoo.co.id] \\ ${ }^{\S}$ Corresponding Author
}

\begin{abstract}
One of multivariate analysis application was used to see the relationship between two or more quantitative variable and objects within. Multivariate analysis which used in this case is correspondence analysis. This paper will be done correspondence analysis application in order to see the characteristic of tourism business in Bali. In this study it can be seen the characteristic of tourism business in Bali in a form of illustration of tourism business situation of each regencies which mapped in two dimensional plots. The result was Karangasem, Buleleng, Gianyar, Jembrana, Tabanan, and Klungkung were in a group because they have the same development of tourism area business and accommodation service business. However tourism business that was developed in Denpasar and Badung was tour and travel and food and beverage business.
\end{abstract}

Keywords: multivariate analysis, correspondence analysis, tourism business

\section{PENDAHULUAN}

Analisis peubah ganda merupakan analisis statistika yang digunakan untuk menganalisis data yang melibatkan lebih dari satu peubah dan beberapa obyek pengamatan (Bilodean, et al [1]). Analisis peubah ganda untuk melihat hubungan dua atau lebih peubah kualitatif serta obyek-obyek yang ada di dalamnya adalah analisis korespondensi. Analisis korespondensi merupakan suatu metode untuk memperoleh penyajian simultan terbaik (the best simultaneous representation) dari gugus data yang berbentuk baris dan kolom matriks (Greenacre [2]). Tujuan dari analisis korespondensi adalah untuk mempermudah dalam melihat karakteristik hubungan antar peubah.

Analisis korespondensi dapat diaplikasikan untuk melihat karakteristik usaha pariwisata di Provinsi Bali. Hal ini perlu dilakukan mengingat pariwisata sampai saat ini masih merupakan motor penggerak perekonomian Bali, kondisi ekonomi Bali sangat bergantung pada kondisi pariwisata Bali (Rai \& Mahadewi [3]). Penelitian ini bertujuan untuk menggambarkan kedekatan kabupaten/kota menurut usaha pariwisata dan memperlihatkan karakteristik usaha pariwisata yang mencirikan kabupaten/kota di provinsi Bali. Data pengamatan mengenai usaha-usaha pariwisata pada daerah kabupaten/kota di Provinsi Bali dinyatakan dalam tabel kontingensi.

Tabel kontingensi dua arah adalah tabel yang mencatat data hasil pengamatan yang melibatkan dua peubah, misalkan $X$ dan $Y$. Jika peubah $X$ sebagai peubah baris terdiri dari $k$ kategori dan peubah $Y$ sebagai peubah kolom terdiri $s$ kategori, maka dapat dibentuk suatu matriks data pengamatan $\boldsymbol{N}$ yang berukuran $k \times s$

$$
\mathbf{N}=\left[\begin{array}{cccc}
n_{11} & n_{12} & \cdots & n_{1 s} \\
n_{21} & n_{22} & \cdots & n_{2 s} \\
\vdots & \vdots & \ddots & \vdots \\
n_{k 1} & n_{k 2} & \cdots & n_{k s}
\end{array}\right]
$$


dengan $n_{i j} \geq 0$ menyatakan data frekuensi pengamatan dari sel $(i, j)$ (Greenacre [2]). Bila $Y_{j}$ adalah peubah kategori kolom ke-j, $j=$ $1,2, \ldots, s ; X_{i}$ adalah peubah kategori baris ke$i, i=1,2, \ldots, k$ maka jumlah pengamatan pada baris ke- $i$ dinyatakan dengan $n_{i .}=$ $\sum_{j=1}^{S} n_{i j} ; i=1,2, \ldots, k ;$ jumlah pengamatan pada kolom ke- $\mathrm{j}$ adalah $n_{. j}=\sum_{i=1}^{k} n_{i j} ; j=$ $1,2, \ldots, s ;$ dan jumlah total pengamatan dinyatakan dengan $n_{. .}=\sum_{i=1}^{k} \sum_{j=1}^{S} n_{i j}$. Matriks $\boldsymbol{N}$ juga dapat disajikan dalam bentuk tabel kontingensi seperti Tabel 1.

Tabel 1. Tabel Kontingensi Dua Arah

$$
\begin{array}{llllll}
Y_{1} & Y_{2} & Y_{3} & \cdots & Y_{j} & \text { Total }
\end{array}
$$

$\begin{array}{ccccccc}\boldsymbol{X}_{\mathbf{1}} & n_{11} & n_{12} & n_{13} & \cdots & n_{1 s} & n_{1 .} \\ \boldsymbol{X}_{\mathbf{2}} & n_{21} & n_{22} & n_{23} & \cdots & n_{2 s} & n_{2 .} \\ \boldsymbol{X}_{\mathbf{3}} & n_{31} & n_{32} & n_{33} & \cdots & n_{3 s} & n_{3 .} \\ \vdots & \vdots & \vdots & \vdots & \ddots & \vdots & \vdots \\ \boldsymbol{X}_{\boldsymbol{k}} & n_{k 1} & n_{k 2} & n_{k 3} & \cdots & n_{k s} & n_{k .} .\end{array}$

Total $\begin{array}{llllll}n_{.1} & n_{.2} & n_{.3} & \cdots & n_{. s} & n_{. .}\end{array}$

Untuk mengetahui ada tidaknya hubungan antara dua peubah kategori dalam tabel kontingensi dilakukan dengan Uji Chi Kuadrat $\left(\chi^{2}\right)$.

$$
\begin{aligned}
\chi^{2} & =\sum_{i=1}^{k} \sum_{j=1}^{S} \frac{\left(n_{i j}-E_{i j}\right)^{2}}{E_{i j}} \\
E_{i j} & =\frac{\left(n_{i .}\right)\left(n_{. j}\right)}{n_{.}}
\end{aligned}
$$

dengan

$n_{i j}=$ banyaknya individu yang diamati pada baris ke- $i$ dan kolom ke- $j$

$E_{i j}=$ banyaknya individu yang diharapkan pada baris ke- $i$ dan kolom ke- $j$

Bila $\chi_{\text {hitung }}^{2}>\chi_{\alpha(k-1)(s-1)}^{2}$ menunjukkan bahwa pada taraf nyata $\alpha$ terdapat hubungan antara kedua peubah kategori dalam tabel kontingensi.
Matriks kepadatan peluang $\mathbf{P}$ dinyatakan sebagai:

$$
\begin{aligned}
\mathbf{P} & =\frac{1}{n . .} \mathbf{N}=\frac{1}{n . .}\left[\begin{array}{cccc}
n_{11} & n_{12} & \cdots & n_{1 s} \\
n_{21} & n_{22} & \cdots & n_{2 s} \\
\vdots & \vdots & \ddots & \vdots \\
n_{k 1} & n_{k 2} & \cdots & n_{k s}
\end{array}\right] \\
& =\left[\begin{array}{cccc}
p_{11} & p_{12} & \cdots & p_{1 s} \\
p_{21} & p_{22} & \cdots & p_{2 s} \\
\vdots & \vdots & \ddots & \vdots \\
p_{k 1} & p_{k 2} & \cdots & p_{k s}
\end{array}\right]
\end{aligned}
$$

Vektor-vektor yang unsur-unsurnya merupakan jumlah elemen masing-masing baris dan jumlah elemen masing-masing kolom dari matriks $\mathbf{P}$ selanjutnya secara berturut-turut dinotasikan dengan $\mathbf{r}$ dan $\mathbf{c}$, dengan:

$$
\mathbf{r}=\left[\begin{array}{c}
p_{1 .} \\
p_{2 .} \\
\vdots \\
p_{k .}
\end{array}\right] \quad \text { dan } \mathbf{c}=\left[\begin{array}{c}
p_{.1} \\
p_{.2} \\
\vdots \\
p_{. s}
\end{array}\right]
$$

Matriks diagonal $\mathbf{D}_{\mathbf{r}}$ berukuran $k \times k$ dan $\mathbf{D}_{\mathbf{c}}$ berukuran $s \times s$ dengan unsur-unsur diagonal utamanya merupakan unsur-unsur dari vektor $\mathbf{r}$ dan c dinyatakan sebagai:

$$
\begin{aligned}
& \mathbf{D}_{\mathbf{r}}=\left[\begin{array}{cccc}
p_{1 .} & 0 & \cdots & 0 \\
0 & p_{2 .} & \cdots & 0 \\
\vdots & \vdots & \ddots & \vdots \\
0 & 0 & \cdots & p_{k .}
\end{array}\right] ; \\
& \mathbf{D}_{\mathbf{c}}=\left[\begin{array}{cccc}
p_{.1} & 0 & \cdots & 0 \\
0 & p_{.2} & \cdots & 0 \\
\vdots & \vdots & \ddots & \vdots \\
0 & 0 & \cdots & p_{. s}
\end{array}\right]
\end{aligned}
$$

Selanjutnya ditentukan matriks profil baris dan profil kolom. Matriks profil baris dari $\mathbf{P}$ didefinisikan sebagai setiap elemen matriks $\mathbf{P}$ dibagi oleh jumlah elemen masing-masing baris. Matriks profil kolom didefinisikan dengan cara yang sama. Matriks profil baris dinyatakan dengan $\mathbf{R}$ dan matriks profil kolom dengan $\mathbf{C}$.

$\mathbf{R}=\mathbf{D}_{\mathbf{r}}^{-1} \mathbf{P}=\left[\begin{array}{cccc}\frac{p_{11}}{p_{1 .}} & \frac{p_{12}}{p_{1 .}} & \cdots & \frac{p_{1 s}}{p_{1}} \\ \frac{p_{21}}{p_{2 .}} & \frac{p_{22}}{p_{2 .}} & \cdots & \frac{p_{2 s}}{p_{2}} \\ \vdots & \vdots & \ddots & \vdots \\ \frac{p_{k 1}}{p_{k .}} & \frac{p_{k 2}}{p_{k .}} & \cdots & \frac{p_{k s}}{p_{k .}}\end{array}\right]=\left[\begin{array}{c}r_{1}{ }^{T} \\ r_{2}{ }^{T} \\ \vdots \\ r_{k}^{T}\end{array}\right]$ 
$\mathbf{C}=\boldsymbol{D}_{\boldsymbol{c}}^{-1} \boldsymbol{P}^{T}=\left[\begin{array}{cccc}\frac{p_{11}}{p_{.1}} & \frac{p_{21}}{p_{.1}} & \cdots & \frac{p_{k 1}}{p_{.1}} \\ \frac{p_{12}}{p_{.2}} & \frac{p_{22}}{p_{.2}} & \cdots & \frac{p_{k 2}}{p_{.2}} \\ \vdots & \vdots & \ddots & \vdots \\ \frac{p_{1 s}}{p_{. s}} & \frac{p_{2 s}}{p_{. s}} & \cdots & \frac{p_{k s}}{p_{s}}\end{array}\right]=\left[\begin{array}{c}c_{1}{ }^{T} \\ c_{2}{ }^{T} \\ \vdots \\ c_{s}{ }^{T}\end{array}\right]$

notasi $\mathrm{T}$ menyatakan transpos matriks.

Nilai inersia menunjukkan kontribusi dari baris ke- $i$ pada inersia total. Inersia total adalah jumlah bobot kuadrat jarak titik-titik ke pusat massa yang didefinisikan sebagai berikut.

Inersia total baris:

in $(a)=\sum r_{i .}\left(r_{i .}-c\right)^{\prime} D_{c}^{-1}\left(r_{i .}-c\right)$

Inersia total kolom:

$$
\text { in }(b)=\sum c_{j .}\left(c_{j .}-r\right)^{\prime} D_{r}{ }^{-1}\left(c_{j .}-r\right)
$$

(Greenacre [2]).

Nilai-nilai $\quad \lambda_{1}{ }^{2}, \ldots, \lambda_{i}{ }^{2}$ diinterpretasikan sebagai besar kontribusi yang diberikan pada total inersia oleh masing-masing dimensi pertama, kedua, dan seterusnya, sehingga besaran relatif untuk mengukur banyak informasi yang hilang dirumuskan sebagai:

$$
L=1-\frac{\sum_{i}^{d} \lambda_{i}{ }^{2}}{\sum_{i}^{m} \lambda_{i}{ }^{2}}
$$

\section{METODE PENELITIAN}

Data yang digunakan dalam penelitian ini adalah data Direktori 2014 dari Dinas Pariwisata Provinsi Bali. Data ini merupakan data mengenai banyak atau frekuensi jenis usaha pariwisata pada masing-masing kabupaten/kota di Provinsi Bali yang meliputi usaha daya tarik wisata, usaha kawasan pariwisata, usaha jasa transportasi wisata, usaha jasa perjalanan wisata, usaha jasa makanan dan minuman, usaha penyedia ako-modasi, penyelenggara pertemuan, perjalanan insentif, konferensi, dan pameran, usaha jasa pramuwisata, dan usaha wisata tirta. Langkah-langkah yang dilakukan dalam analisis data pada tulisan ini sebagai berikut.

1. Melakukan Analisis Deskriptif untuk melihat jumlah usaha pariwisata yang terdapat pada masing-masing wilayah di provinsi Bali dengan menggunakan tabel kontingensi.
2. Melakukan Analisis Hubungan antar peubah untuk melihat hubungan ketergantungan pada peubah wilayah dengan peubah usaha pariwisata.

3. Melakukan Analisis Korespondensi antar peubah wilayah dan peubah usaha pariwisata dengan tahap sebagai berikut:

a. Membentuk tabel profil baris dan tabel profil kolom berdasarkan tabel kontingensi sebelumnya.

b. Menghitung nilai proporsi inersia baris dan kolom berdasarkan profil baris dan profil kolom pada langkah a.

c. Menghitung nilai singular value decomposition berdasarkan inersia baris dan inersia kolom untuk menampilkan titik koordinat masing-masing variabel wilayah dan variabel usaha kedalam plot dua dimensi.

d. Membuat kesimpulan dengan merangkum hasil analisis sehingga memberikan informasi mengenai karakteristik usaha pariwisata pada kabupaten/kota di Provinsi Bali.

\section{HASIL DAN PEMBAHASAN}

Analisis deskriptif data penelitian menunjukkan bahwa usaha pariwisata di Provinsi Bali pada tahun 2014 sebanyak 6855 usaha, dimana usaha pariwisata paling banyak terdapat di kabupaten Badung yaitu sebesar $35,2 \%$. Sedangkan kabupaten Bangli memiliki jumlah usaha pariwisata paling sedikit dibandingkan wilayah lainnya yaitu hanya $1,07 \%$.

Nilai indeks skweness pada peubah wilayah kabupaten/kota dan peubah usaha pariwisata berturut-turut sebesar 1,39 dan 20,64. Ini menunjukan bahwa data pada peubah wilayah relatif berdistribusi normal, karena indeks skwenessnya berada pada rentang $[-2,00 ; 2,00]$. Dengan menggunakan uji Goodman \& Kruskal Tau, didapatkan hasil yang sangat signifikan dengan P-value 0,000 dan Asymptoot Standard Error sebesar 0,004, berarti pola hubungan antara peubah wilayah dan usaha pariwisata relatif berbentuk simetrik. Dengan demikian 
dapat dinyatakan bahwa karakteristik usaha pariwisata dan wilayah kabupaten/kota di provinsi Bali saling memengaruhi.

Analisis korespondensi diawali dengan mengkaji profil baris dan profil kolom. Hal ini bertujuan untuk mengetahui jenis usaha

Tabel 2. Nilai Profil Baris

\begin{tabular}{lcccccccccc}
\hline Wilayah & \multicolumn{10}{c}{ Usaha } \\
\cline { 2 - 8 } & $\mathrm{X} 1$ & $\mathrm{X} 2$ & $\mathrm{X} 3$ & $\mathrm{X} 4$ & $\mathrm{X} 5$ & $\mathrm{X} 6$ & $\mathrm{X} 7$ & $\mathrm{X} 8$ & $\mathrm{X} 9$ \\
\hline Denpasar & .007 & .001 & .073 & .163 & .412 & .210 & .005 & .056 & .072 & 1.0 \\
Badung & .014 & .001 & .009 & .058 & .478 & .397 & .001 & .015 & .027 & 1.0 \\
Gianyar & .046 & .002 & .005 & .017 & .378 & .552 & .000 & .002 & .000 & 1.0 \\
Tabanan & .117 & .005 & .019 & .015 & .155 & .675 & .000 & .000 & .015 & 1.0 \\
Jembrana & .082 & .011 & .005 & .000 & .446 & .457 & .000 & .000 & .000 & 1.0 \\
Buleleng & .025 & .005 & .005 & .002 & .271 & .665 & .000 & .000 & .026 & 1.0 \\
Karangasem & .026 & .000 & .000 & .002 & .209 & .679 & .000 & .000 & .084 & 1.0 \\
Klungkung & .156 & .009 & .009 & .009 & .367 & .413 & .000 & .000 & .037 & 1.0 \\
Bangli & .527 & .000 & .000 & .014 & .230 & .216 & .000 & .000 & .014 & 1.0 \\
Mass & .033 & .002 & .020 & .058 & .390 & .444 & .001 & .017 & .035 & \\
\hline
\end{tabular}

Keterangan:

$X_{1}=$ Usaha Daya Tarik Wisata

$X_{2}=$ Usaha Kawasan Pariwisata

$X_{3}=$ Usaha Jasa Transportasi Wisata

$X_{4}=$ Usaha Jasa Perjalanan Wisata

$X_{5}=$ Usaha Jasa Makanan dan Minuman

$X_{6}=$ Usaha Penyedia Akomodasi

$X_{7}=$ Usaha Penyelenggara Pertemuan,

Perjalanan Insentif, Konferensi, dan

Pameran

$X_{8}=$ Usaha Jasa Pramu Wisata

$X_{9}=$ Usaha Wisata Tirta

Profil baris dalam Tabel 2 menunjukkan bahwa nilai massa terbesar adalah 0.444 yang terdapat pada usaha penyediaan akomodasi $\left(\mathrm{X}_{6}\right)$ yang merupakan modus pada data ini. Nilai ini menyatakan bahwa usaha penyedia akomodasi merupakan usaha dengan jumlah terbesar di Provinsi Bali. Keberadaan usaha ini terdapat di pariwisata apa yang berkembang di suatu wilayah kabupaten/kota dan suatu jenis usaha pariwisata berkembang di wilayah kabupaten/ kota mana saja. Nilai profil baris dan profil kolom disajikan dalam Tabel 2 dan Tabel 3. semua kabupaten/kota sehingga dapat dikatakan bahwa usaha akomodasi cenderung berkembang di seluruh wilayah di Provinsi Bali. Khususnya Kabupaten Gianyar, Tabanan, Jembrana, Buleleng, Karangasem dan Klungkung mengelompok pada usaha penyediaan akomodasi, menunjukkan secara umum usaha pariwisata yang cenderung berkembang di wilayah tersebut adalah usaha penyediaan akomodasi. Kota Denpasar dan Kabupaten Badung mengelompok pada usaha jasa makanan dan minuman $\left(\mathrm{X}_{5}\right)$, yang berarti secara umum usaha pariwisata yang cenderung berkembang di kedua wilayah tersebut adalah usaha jasa makanan dan minuman. Karak-teristik yang juga ditunjukkan dari nilai profil baris adalah suaha pariwisata yang cenderung berkembang di kabupaten Bangli adalah usaha daya tarik wisata $\left(\mathrm{X}_{1}\right)$.

Tabel 3. Nilai Profil Kolom

\begin{tabular}{|c|c|c|c|c|c|c|c|c|c|c|}
\hline \multirow[t]{2}{*}{ Wilayah } & \multicolumn{10}{|c|}{ Usaha } \\
\hline & $\mathrm{X} 1$ & $\mathrm{X} 2$ & X3 & $\mathrm{X} 4$ & $\mathrm{X} 5$ & X6 & X7 & X8 & X9 & Mass \\
\hline Denpasar & .044 & .077 & .734 & .574 & .215 & .096 & .778 & .678 & .426 & .204 \\
\hline Badung & .145 & .231 & .158 & .353 & .431 & .315 & .222 & .304 & .270 & .351 \\
\hline Gianyar & .268 & .154 & .043 & .055 & .187 & .241 & .000 & .017 & .000 & .193 \\
\hline Tabanan & .105 & .077 & .029 & .008 & .012 & .046 & .000 & .000 & .013 & .030 \\
\hline Jembrana & .066 & .154 & .007 & .000 & .031 & .028 & .000 & .000 & .000 & .027 \\
\hline Buleleng & .061 & .231 & .022 & .003 & .058 & .124 & .000 & .000 & .063 & .083 \\
\hline Karangasem & .066 & .000 & .000 & .003 & .046 & .130 & .000 & .000 & .207 & .085 \\
\hline Klungkung & .075 & .077 & .007 & .003 & .015 & .015 & .000 & .000 & .017 & .016 \\
\hline Bangli & .171 & .000 & .000 & .003 & .006 & .005 & .000 & .000 & .004 & .011 \\
\hline Active Margin & 1.00 & 1.00 & 1.00 & 1.00 & 1.00 & 1.00 & 1.00 & 1.00 & 1.00 & \\
\hline
\end{tabular}


Nilai massa pada profil kolom menunjukkan bahwa $35,1 \%$ usaha pariwisata berada di Kabupaten Badung, sebesar 20,4\% di Kota Denpasar, di Kabupaten Gianyar sebesar 19,3\% dan di kabupaten lainnya prosentase usaha pariwisata bernilai relative kecil. Usaha pariwisata yang cenderung berkembang di Kabupaten Badung adalah Usaha Kawasan Pariwisata, Usaha Jasa Makanan dan Minuman, serta Usaha Penyedia Akomodasi. Untuk Kota
Denpasar usaha pariwisata yang berkembang adalah Usaha Jasa Transportasi Wisata, Usaha Jasa Perjalanan Wisata, usaha Penyelenggara Pertemuan, Perjalanan Insentif, Konferensi, dan Pameran, serta Usaha Wisata Tirta. Di Kabupaten Gianyar, jenis usaha pariwisata yang berkembang adalah Usaha Daya Tarik Wisata. Tabel 4.

Tabel 4. Nilai Proporsi Inersia

\begin{tabular}{|c|c|c|c|c|c|c|}
\hline \multirow[t]{2}{*}{ Dimension } & \multirow[t]{2}{*}{ Singular Value } & \multirow[t]{2}{*}{ Inertia } & \multirow[t]{2}{*}{ Chi Square } & \multirow[t]{2}{*}{ Sig. } & \multicolumn{2}{|c|}{ Proportion of Inertia } \\
\hline & & & & & $\begin{array}{l}\text { Accounted } \\
\text { for }\end{array}$ & Cumulative \\
\hline 1 & .440 & .193 & & & .584 & .584 \\
\hline 2 & .304 & .092 & & & .279 & .864 \\
\hline 3 & .187 & .035 & & & .106 & .970 \\
\hline 4 & .087 & .008 & & & .023 & .993 \\
\hline 5 & .047 & .002 & & & .008 & 1.000 \\
\hline 6 & .000 & .000 & & & .000 & 1.000 \\
\hline Total & & .331 & 2267.34 & $.000^{\mathrm{a}}$ & 1.000 & 1.000 \\
\hline
\end{tabular}

Nilai Chi-Square sebesar 2267,34 dan P-Value sebesar 0,000 memperlihatkan bahwa terdapat hubungan yang sangat signifikan antara usaha pariwisata dengan wilayah kabupaten/kota di Provinsi Bali. Proporsi inersia kumulatif pada dua dimensi sebesar $86,4 \%$ menunjukkan bahwa apabila dipetakan dalam dua dimensi, keragaman data atau karakteristik data yang mampu dijelaskan sebesar $86,4 \%$ dari keragaman data seluruhnya. Maka banyak informasi yang hilang pada pemetaan dua dimensi sebesar $\mathrm{L}=13,6 \%$.

Hasil analisis korespondensi antara peubah wilayah kabupaten/kota dan peubah usaha pariwisata di Provinsi Bali yang ditampilkan dalam plot 2 dimensi pada Gambar 1. Usaha pariwisata, usaha jasa perjalanan wisata, usaha penyelenggara pertemuan, perjalanan insentif, konferensi, dan pameran, serta usaha wisata tirta, mengelompok pada wilayah Denpasar. Hal ini memperlihatkan adanya kesamaan karakteristik antara usaha Jasa Perjalanan Wisata, usaha Penyelenggara Pertemuan, Perjalanan Insentif, Konferensi, dan Pameran, serta Usaha Wisata Tirta yaitu memiliki perkembangan yang hampir merata di wilayah Kota Denpasar atau dapat pula diungkapkan bahwa usaha-usaha tersebut semuanya berkembang di kota Denpasar.

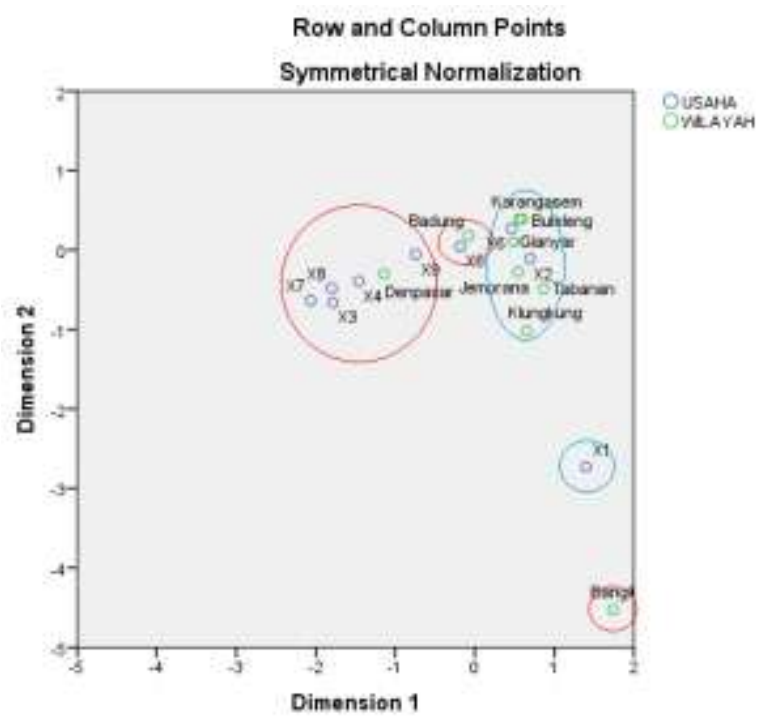

Gambar 1. Pemetaan Karakteristik Wilayah dan Usaha Pariwisata

Usaha jasa makanan dan minuman menjadi penciri wilayah Kabupaten Badung, memperlihatkan bahwa perkembangan usaha jasa makanan dan minuman memiliki perkembangan yang sangat baik di kabupaten Badung dibandingkan jenis usaha lainnya. Di Provinsi Bali, Kabupaten Badung merupakan wilayah yang memiliki perkembangan usaha 
jasa makanan dan minuman yang paling tinggi dibanding wilayah lainnya.

Usaha kawasan pariwisata dan usaha penyedia akomodasi mengelompok pada wilayah Karangasem, Jembrana, Buleleng, Gianyar, Tabanan, dan Klungkung. Hal ini menunjukan bahwa usaha kawasan pariwisata dan usaha penyedia akomodasi memiliki perkembangan yang merata di wilayah Karangasem, Jembrana, Buleleng, Gianyar, Tabanan, dan Klungkung.

Usaha daya tarik wisata berada jauh dari usaha pariwisata lainnya, serta tidak ada wilayah tertentu yang posisinya berdekatan dengan usaha ini. Kondisi ini menggambarkan bahwa usaha daya tarik wisata bukan penciri khusus pada satu wilayah, atau tidak ada wilayah yang sangat dominan pada usaha daya tarik wisata, atau dapat juga diungkapkan bahwa perkembangan usaha daya tarik wisata merata di seluruh wilayah kabupaten/kota di Provinsi Bali. Wilayah Bangli juga berada jauh dari wilayah dan usaha pariwisata lainnya, hal tersebut memperlihatkan wilayah Kabupaten Bangli memiliki perkembangan usaha pariwisata yang sangan berbeda dari wilayah lainnya, bahkan wilayah ini dapat dikatakan wilayah yang memiliki perkembangan yang paling rendah diban-dingkan wilayah lainnya, wilayah ini hanya memiliki perkembangan pariwisata yang baik pada usaha daya tarik wisata, hal itu dapat dilihat bahwa posisi wilayah ini paling dekat dengan usaha daya tarik wisata.

\section{KESIMPULAN}

Usaha Jasa Transportasi Wisata, Usaha Jasa Perjalanan Wisata, usaha Penyelenggara Pertemuan, Perjalanan Insentif, Konferensi, dan Pameran, serta Usaha Wisata Tirta yaitu memiliki perkembangan yang lebih baik di wilayah Kota Denpasar dibandingkan di wilayah lainnya. Usaha jasa makanan dan minuman memiliki perkembangan yang sangat pesat di kabupaten badung dibandingkan jenis usaha lainnya dan bahkan Kabupaten Badung yang memiliki perkembangan usaha jasa makanan dan minuman yang paling baik diantara wilayah lainnya di Provinsi Bali. Usaha kawasan pariwisata dan usaha penyedia akomodasi memiliki perkembangan yang merata di wilayah Karangasem, Jembrana, Buleleng, Gianyar, Tabanan, dan Klungkung. Kabupaten Bangli memiliki perkembangan usaha pariwisata yang sangat berbeda dengan wilayah lainnya, pencirinya adalah usaha daya tarik wisata, dilihat dari posisi Bangli paling dekat dengan usaha daya tarik wisata.

\section{DAFTAR PUSTAKA}

[1] Bilodean, Martin and Brenner. D. 1999. Theory of Multivariate Statistics. Springer. New York.

[2] Greenacre, M. J. 1984. Theory and Applications of Correspondence Analysis, Academic Press Inc. London.

[3] Rai, I.G.B.U. dan N.M.E. Mahadewi. 2012. Metode Penelitian Pariwisata dan Perhotelan. Andi. Yogyakarta. 